\title{
Working Process and Resulting Properties of Continuously Casting Steel ${ }^{*}$
}

\author{
By Kiyoto USHIJIMA**
}

\begin{abstract}
Synopsis
The role of continuous casting of steel as a connecting process between steel making and shaping is reviewed. Various types of continuous casting and shapes of cast pieces and their properties are described. Continuously cast steel can be made to final products through substantially similar processing for products to the conventional process without blooming. And it is described that the quality of continuously cast product is identical or rather superior sometimes to that of the conventional ingot-blooming process in spite of the fact that its processing ratio is less than that of the conventional process.
\end{abstract}

\section{Preface}

The quantities of steel supplied by continuous casting have been increased year by year, and in 1970 , it was more than $10 \%$ of the overall production of crude steel in the world, and it is forecast that continuous casting will substitute for steel ingot-blooming method successively in the future. Someone forecast that the ratio of this continuous casting will reach to an extent of about $20 \%$ in the future of five years. ${ }^{1)}$

As a trend in recent years, the propagation of continuous casting is remarkable at both extremities of large capacity machine to cast large size slab as the material for steel plate or sheet in mass-production factory and of small machine to produce small billet for rod or wire. The intermediate dimension being necessary to perform blooming process loses one of main objects of continuous casting, and the abovementioned trend may be said to be natural.

Anyhow, on the continuous casting method which is propagating year by year in pursuing the merits such as simplification of the process, improvement in the yield, labor and energy-savings and mechanization, it will be described on its charging region, processing and properties of cast steel.

\section{Region of Continuous Casting}

As for the history of continuous casting, there was an idea at the beginning that the same sectional shape as the product is to be cast directly and continuously from molten steel. However, in the present feature accomplished as a modern installation for mass-production, semi-product with comparatively simple sectional shape such as square or rectangular is cast continuously. This reason is that various physical properties of steel such as high melting point, low heat conduction rate, contraction, segregation etc. appear as limitation from the aspects of both quality and operation during its solidifying process. Especially in a modern mass-production system for steel, continuous casting must have a trend toward simplification and large capacity as an intermediate installation between melting furnace and rolling installation of a large capacity.

On the one hand, however, a natural effort for casting so as to have a similar shape to the final product has been continued from the aspect of rationalization of manufacturing process for steel, thus a number of trials have been made for continuous casting of various deformed sections. While, so-called "in-line reduction system " in which a rough rolling installation is built in continuous casting machine, has been industrialized as a system satisfying these contrary requirements, although it recedes one step from the object of the rationalization of the process.

\section{Billet with Deformed Section}

As a trial to cast billet with a section to be as similar as possible to the sectional shape of the final product under the purpose of simplification of the process as described above, such a shape as shown in Fig. 1 has been considered hitherto. ${ }^{2)}$ Among these, Beam Blank so-called "dog-bone" and elliptic, polygonal, hollow or round shape for steel pipe have been industrialized or are near to industrialization.

\section{Wide Flange Sections}

BISRA in England has advanced a research on the continuous casting of deformed sectional billet since the beginning of 1960 . A shape realized first was so-called "Wey-bridge method", in which multiple

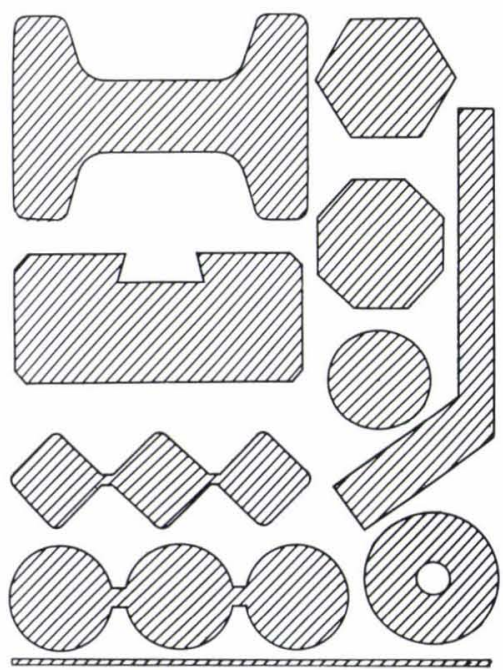

Fig 1. Continuously cast piece of various deformed section tested hitherto ${ }^{21}$ 
numbers of square billet sections are arranged in a row along its diagonal line. ${ }^{3)}$ This was devised to improve the casting efficiency for small size billet, and it was intended to cast multiple numbers of billets at the same time by one strand and to gain multiple numbers of billets by cutting the connected parts of each billet using gas after solidification. But this method did not extend to an installation for massproduction.

But, Sheffield Laboratory of BISRA advanced subsequently a joint research with Algoma Steel Corp. in Canada, and they succeeded in a fundamental experiment on the continuous casting of Beam Blank in the former half of 1960's decennary. ${ }^{4)}$ Algoma Steel Corp. constructed a continuous casting machine of two strands for beam blank connected with $110 \mathrm{t}$ converter in 1968 based on the experimental result. ${ }^{5}$ ) Sectional shape of beam blank is shown in Fig. 2. It is said that the shape of $\mathrm{A}-\mathrm{C}$ is cast mainly in Algoma, and that wide flange sections having the dimensions of several tens kinds are rolled from these blanks.

It is necessary, of course, to set up an installation which is more complicated than that for simple slab or billet, having tundish, mold, roller apron, spray device, or every other parts of continuous casting machine. For example, with regard to the roller apron, it is necessary to be supported by four couples of roller at the position just below the mold as shown in Fig. 3, and it is obliged to adopt such a system that the number of couples of roller are decreased successively toward two couples and then one couple is used to advance the solidification of dog-bone. And such a spray as the cooling is made in many directions becomes necessary as shown in Fig. 4. Thus, its economical burden at casting side is larger than that for the ordinary cast with square or rectangular section, but it is appraised the merit contributing to the manufacturing of a shaped steel such as omission of the blooming process or improvement in the yield estimated as approximately $10 \%$, and the operation of a continuous casting machine for $\mathrm{H}$-shaped steel material has recently been started in Japan.

\section{Steel Pipe}

With regard to steel pipe materials, it has been tried some continuous casting methods such as casting of billet with elliptic section of e.g. $50 \mathrm{~mm} \times 80 \mathrm{~mm}$ or $80 \mathrm{~mm} \times 105 \mathrm{~mm}$ in the early period of 1960's decennary, ${ }^{6}$ ) billet with regular hexagonal section of $90 \mathrm{~mm}$ in the opposite side distance in the early period of 1960's decennary ${ }^{7}$ ) and billet with circular section of $115 \mathrm{~mm}$ diameter ${ }^{8)}$ and a part of these has been brought into production. ${ }^{9)}$ In every cases, it is considered that such factors as the design and the arrangement of mold and roller apron are important for the casting technique. Every one of billets manufactured by these ordinary methods is not always perfect with respect to such factors as the plainness of the surface and the residual porosity at the center. Accordingly, cylindrical hollow billet or centrifugal continuous casting method has been developed.

(1) Cylindrical Hollow Billet

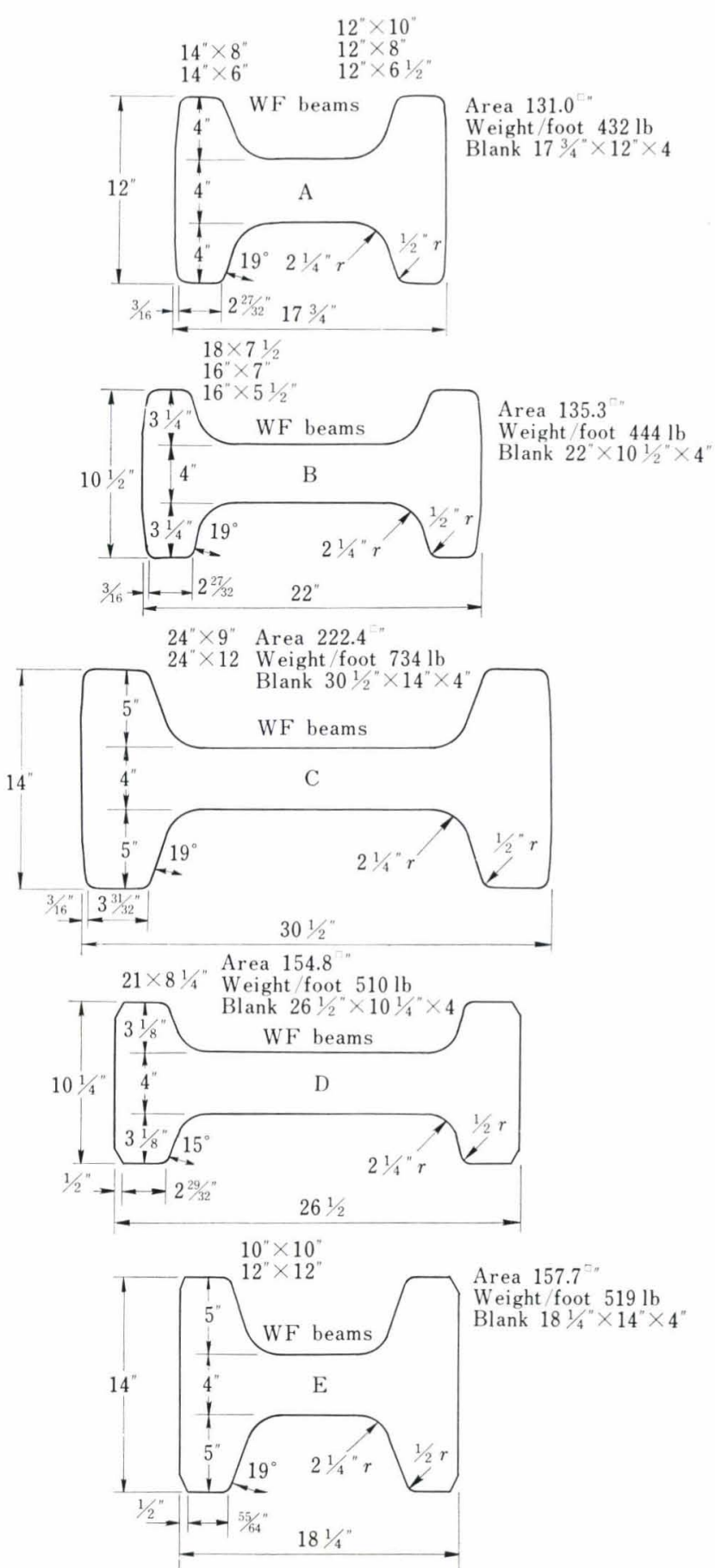

Fig. 2. Cross-sectional profile of Beam Blank at Algoma Steel $^{5)}$

This research has been advanced in West Germany in 1950's decennary by Huckingen of Mannesmann A.G., and succeeded in continuous casting of hollow billect of $300 \mathrm{~mm}$ in outer diameter and $100 \mathrm{~mm}$ in inner diameter. It is reported that Gelsenkirchen Works of the same company succeeded thereafter in casting of cylindrical hollow billet of $450 \mathrm{~mm}$ in outer diameter and $100 \mathrm{~mm}$ in inner diameter. ${ }^{10}$ )

Bohler in Austria made a research on the continuous casting of cylindrical hollow billet in 1950's decennary. The casting of cylindrical hollow billet was realized by such a method that the casting being performed along a circular arc as shown in Fig. 5, 


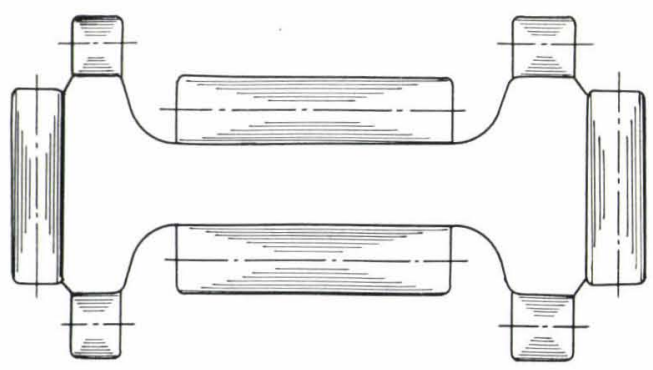

Roller apron sections $1 \mathrm{~A}$ top and $1 \mathrm{~A}$ bottom 7 sets of rolls each

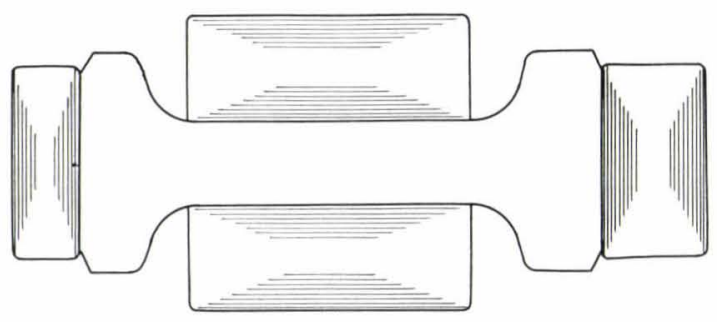

Roller apron sections $1 \mathrm{~B}$ and 2

11 sets of rolls each

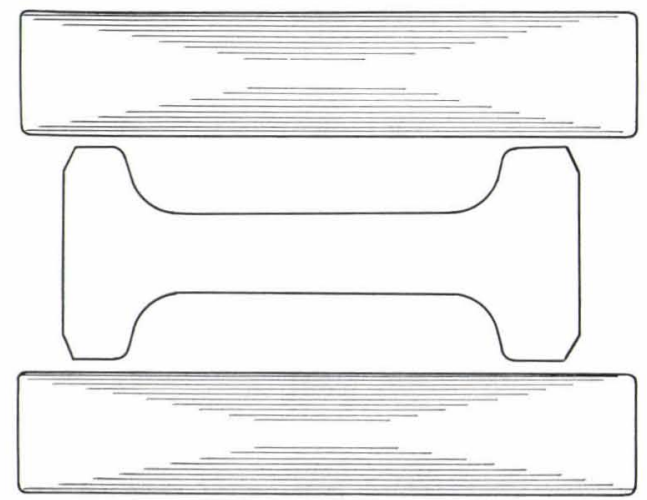

Roller apron sections 3 and 4 12 sets of rolls each

Fig. 3. Roller Aprons in secondary cooling zone for Dogbone $^{5 \text { ) }}$

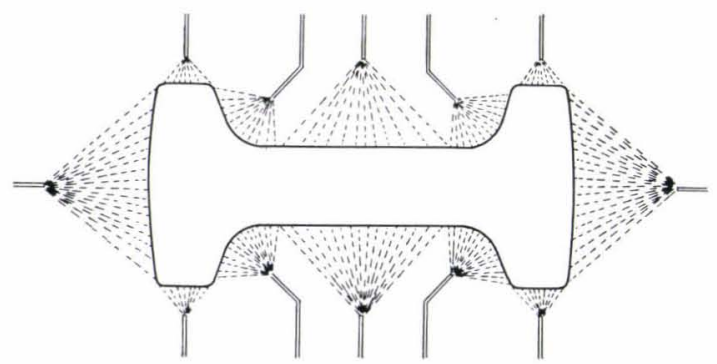

Fig. 4. Spray in secondary cooling zone for Dog-bone $\mathrm{e}^{5)}$

and the cylindrical shell part only being taken out by drawing up the billet while it is yet in the unsolidified state at of $180^{\circ} \mathrm{C}$ from the casting surface. ${ }^{11)}$ As the result, a hollow billet of $150 \mathrm{~mm}$ outer diameter was gained as shown in Photo. 1.12) With regard to wall thickness, it is reported that the thickness can be adjusted by selecting suitably both casting speed and cooling speed.

However, every one of the above-mentioned meth-

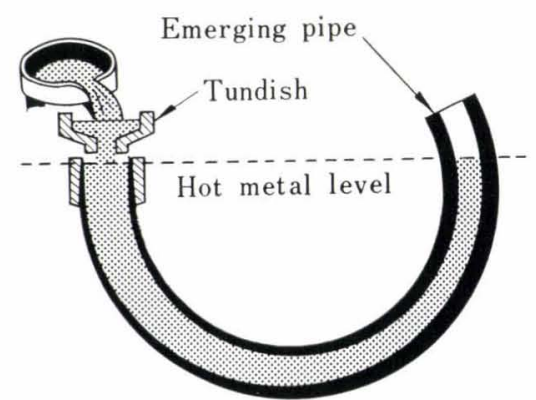

Fig. 5. Model of continuous casting method for Bohler-type cylindrical hollow billet ${ }^{11}$
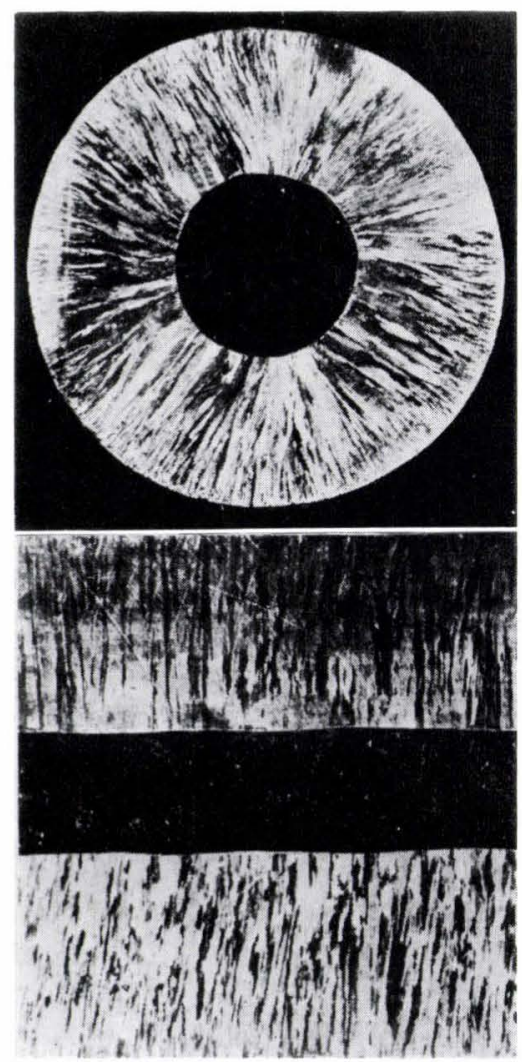

Photo. 1. Section of cylindrical hollow billet cast continuously $^{12)}$

ods has many problems on the installation itself and the operation so that it is not yet attainable to propagate as the installation for mass-production. An installation which is exhibiting the actual results at present as an industrial installation is the centrifugal continuous casting installation, and it is said that solid circular sectional billet, can be efficiently cast in a superior quality by this method, but not cylindrical hollow billet.

(2) Centrifugal Continuous Casting

This is a method in which centrifugal casting and continuous casting are combined as described already. As shown in Fig. 6, casting from upper tundish and drawing of billet downwards are performed continuously while mold, and pinch rolls are rotating together with billet as one body around the axis. ${ }^{13)}$ Billet having more exact circularity can be obtained by this method as compared with the case of ordinary continuous casting, and it is said that not only the 


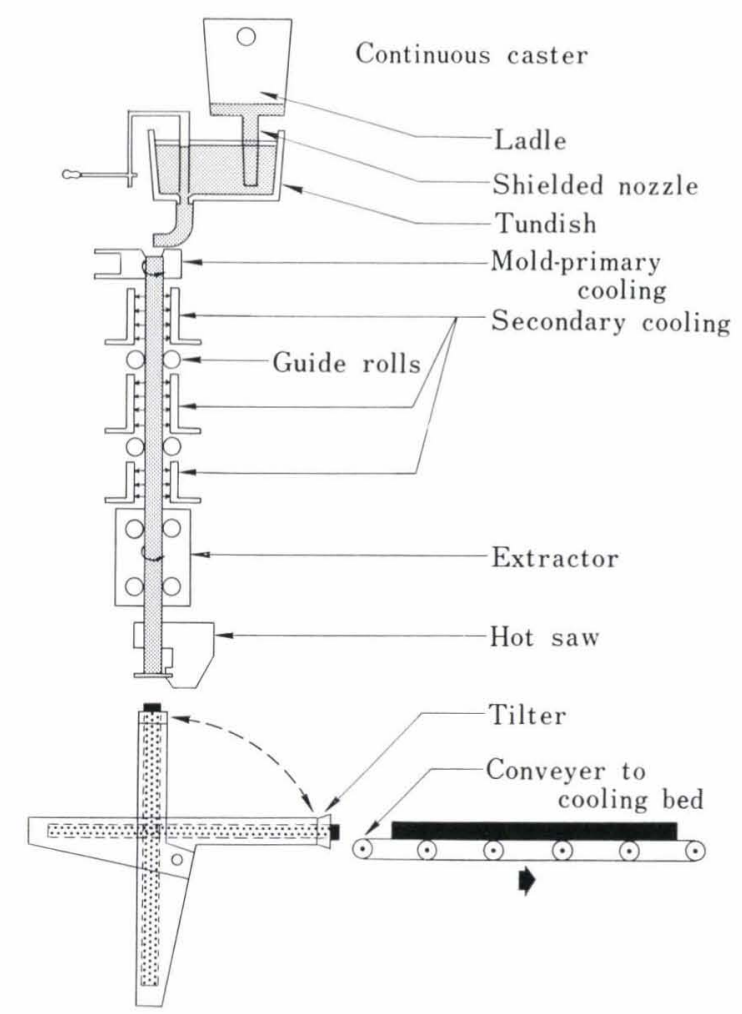

Fig. 6. Model of centrifugal continuous casting method $^{13)}$

surface quality of billet but also the porosity at the axial center part are improved.

This method has been developed by a joint research of Vallourec and SFAG in France in the later period of 1950's decennary. ${ }^{14)}$ Application of this method for the cylindrical hollow billet was examined at the beginning, but at the present, it is limited only to the billet with solid circular section, and the installations for mass-production have already been made in U.S.A. ${ }^{13)}$ and Japan.

\section{In-line Reduction}

"In-line reduction" means a method in which cast billet or slab is roughly rolled with a continuous casting machine subsequently to the casting operation. This idea is based on the aspects that the internal quality of cast piece is improved and that cast pieces of various sectional dimensions are produced from cast pieces with the identical sectional dimension. The former is BSR represented by Bohler, and the latter is a method of U.S. Steel or other method called generally as "sizing mill".

\section{BSR Method}

BSR is an abbreviation of Bohler Strand Reducing, and this is a method by an installation installed at this factory in 1967 based on the research with respect to the solidification of continuous casting billet which has been made since old age. Namely, as shown in a schematic drawing of Fig. 7, it is intended to gain a sound billet without segregation and porosity at the center part by compressing billet at final solidification zone. In practice, a billet of $140 \mathrm{~mm}$ square was cast and billet of $90 \mathrm{~mm}$ square was gained by rolling at the final solidification zone. This method, of

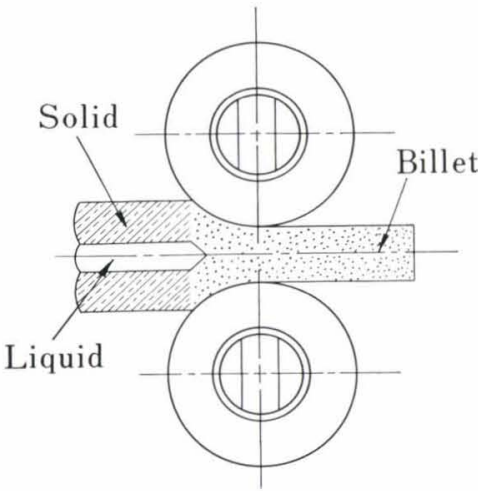

Fig. 7. Model of BSR method

course, is also provided with such a feature that billets with various sectional dimensions can be obtained by casting billets with the identical sectional dimension.

However, this method has many difficulties in applying to the industrial process because exact detection of the final solidification zone or the control of the casting condition brought to the final solidification zone is not so easy under the rolling condition, and moreover, it has such a shortcoming that a crack is apt to produce inside of the billet. Accordingly, in In-line reduction, the rolling process is added in the period after solidification of billet or slab, and it aims to take advantage of the merit that the sectional dimension can be changed. This is so-called "sizing mill " to be described in the following section.

\section{Sizing Mill}

As the installations for bloom or billet belonging to this category, there are such installations as shown in Table 1. In these installations, internal and external parts of the cast piece are heated evenly with a reheating or soaking furnace after passing through drawing rolls, and then it is rolled by horizontal and vertical rolling rolls which are mostly provided with $2 \sim 8$ strands. Thus the billets having the required sectional dimension can be obtained from a billet with a constant sectional dimensions. The maximum rolling ratio is mostly $40 \sim 50 \%$ in sectional area. ${ }^{15-17)}$

In the case of Kishiwada Steel Co,, as an example for billet, there is a soaking furnace connected with two strands continuous casting installations of verticalbending type, and a compressing equipment is directly installed at the rear position. Cast billet is $140 \mathrm{~mm}$ square, and this is rolled to $105 \mathrm{~mm}$ square by compressing device with two vertical and horizontal stands. After then it is sent to the subsequent rolling mill. It is said that the internal quality of billet is improved by this process.

With regard to the sizing mill for slab, a large scale installation was completed for the first time at Gary of U.S. Steel in 1967.18,19) In this installation, a continuous casting machine of vertical-bending type is provided with a heating furnace and a reduction mill which is consisted of three horizontal stands and four vertical stands as shown in Fig. 8, and there is such two cases that a cast slab of $1375 \mathrm{~mm} \times 233 \mathrm{~mm}$ is reduced to the range of $1375 \mathrm{~mm} \times 225 \mathrm{~mm} \sim$ 
$800 \mathrm{~mm} \times 150 \mathrm{~mm}$, and that a cast slab of $1900 \mathrm{~mm} \times$ $233 \mathrm{~mm}$ is reduced to the range of $1900 \mathrm{~mm} \times 225$ $\mathrm{mm} \sim 1000 \mathrm{~mm} \times 183 \mathrm{~mm}$. In every case, the rolling amount is approximately $60 \%$ at maximum. Thereby, casting is limited only to two sectional dimensions, and it is intended to gain the slabs with any required sectional dimension from the said cast dimension.

But, the largest shortcoming of these sizing mills is that it contains a large scale rough rolling process which is nearly equivalent to the blooming process and that the rolling speed of this roughing machine is inefficient since it moves with the same speed as the speed of continuous casting, so the loading condition of rolls becomes rather severe as compared with the case of ordinary blooming. Further, it is considered that the cost of installation is not profitable at all as compared with the ordinary blooming installation since it necessitates a rough rolling installation for

Table 1. Sizing mills used for bloom and billet

\begin{tabular}{|c|c|c|c|}
\hline \multirow{2}{*}{$\begin{array}{l}\text { Name of } \\
\text { company }\end{array}$} & \multicolumn{2}{|c|}{$\begin{array}{l}\text { Sectional size } \\
(\mathrm{mm})\end{array}$} & \multirow{2}{*}{$\begin{array}{l}\text { Rolled amount (\%) } \\
\text { (Sectional area } \\
1-\frac{\text { after rolling) }}{\text { (Sectional area }} \\
\text { as cast) }\end{array}$} \\
\hline & As cast & $\begin{array}{l}\text { After } \\
\text { rough } \\
\text { rolling }\end{array}$ & \\
\hline $\begin{array}{l}\text { Timken Roller } \\
\text { Bearing }\end{array}$ & $240 \times 305$ & 240 Squ. & 38 \\
\hline $\begin{array}{l}\text { George Town } \\
\text { Steel }\end{array}$ & $135 \times 100$ & 100 Squ. & 45 \\
\hline National Steel & $185 \mathrm{Squ}$. & $180 \times 140$ & 39 \\
\hline Inland Steel & $\begin{array}{l}178 \text { Squ. } \\
146 \text { Squ. }\end{array}$ & $\begin{array}{l}127 \text { Squ. } \\
100 \text { Squ. }\end{array}$ & $\begin{array}{l}49 \\
53\end{array}$ \\
\hline U.S. Steel & $190 \mathrm{Squ}$. & $100 \mathrm{Squ}$. & 72 \\
\hline Kishiwada Steel & $140 \mathrm{Squ}$. & 105 Squ. & 44 \\
\hline Bohler & $140 \mathrm{Squ}$. & $96 \mathrm{Squ}$. & 53 \\
\hline
\end{tabular}

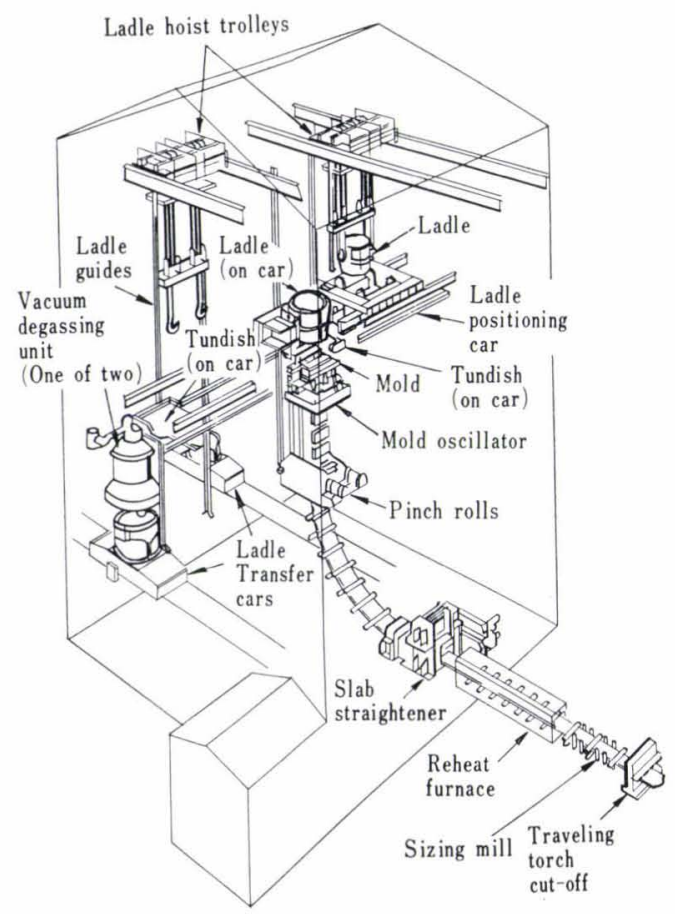

Fig. 8. Continuous casting machine attached with sizing mill by U.S. Steel ${ }^{18)}$ every strand of casting. However, when continuous casting is introduced by the purpose of the utilization of existing rolling installation for small sectional material and of the rationalization of steel making process, billets of larger section are generally stabilized from the operational viewpoint. Accordingly there is some case in which sizing mill is more effective as a conjunction between these installations.

\section{Quality of Continuously Cast Steel}

Prior to the description of the manifest properties of continuously cast steel, it will be briefly described about the quality of cast piece in the as cast state. Most remarkable differences between the continuous casting method and the conventional ingot-blooming method are as follows: (1) while the conventional steel ingots are divided roughly into three kinds of killed steels, semi-killed steel and rimmed steel, there is only one kind of killed steel in the continuous casting at present. (2) while in the conventional method it passes through once a blooming process when it is fed to the subsequent rolling process, continuously cast billet or slab is in the as cast state having porosity in it.

\section{Continuous Casting of Rimmed Steel}

Many trials have been made in the past to manufacture billet or slab of rimmed steel by continuous casting. Typical trials among these will be introduced in this section.

Appleby Frodingham performed several tens times of casting tests for rimmed steel using $225 \mathrm{~mm}$ square billets $^{20}$ ) and found that sound solid skin was hardly formed on the surface of billet. It appeared such defects as the residuals of pin holes and the segregation of element although cast piece having the feature similar to rimmed steel was obtained under the most suitable condition as shown in Photo. 2. Thickness of skin varies sensitively in accordance with the casting temperature and the casting speed, and there is such a tendency that the thickness of skin increases when both factors become lower. Since it is difficult to maintain these conditions within the suitable very narrow range during the period of casting and the operating condition is also severe, the case in which molten steel of more than $60 \mathrm{t}$ out of $80 \mathrm{t}$ produced for

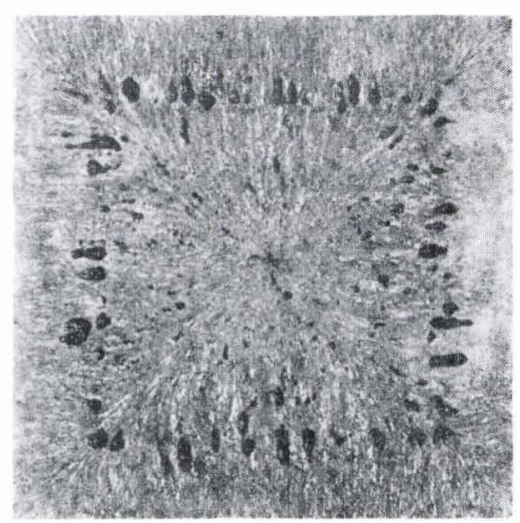

Photo. 2. Cross-section of continuous cast billet of rimmed steel $^{20)}$ 
a heat was successfully cast is only $37 \%$ in 54 heats of casting performed for a period of nine months. It is said that the surface of steel rod rolled from billet thus gained is inferior and that large quantities of surface layer must be removed, and the quality equivalent to Si killed steel can only be obtained by cold drawing.

Steel Co. of Wales in England also performed casting tests for rimmed steel with a slab. ${ }^{21)}$ In this case, there is a problem with regard to the adjustment of rimming action in mold, and the discharging of gas becomes violent gradually and the casting must be stopped at last in many case although one third of initial rimmed steel in a $60 \mathrm{t}$ ladle can be cast normally. It is said that the quality of slab is superior when more violent rimming action is performed.

Further, Dillinger in West Germany also performed the casting tests for rimmed steel with a slab of 1000 $\mathrm{mm} \times 185 \mathrm{~mm},{ }^{22)}$ and found that it was very hard to maintain the contents of carbon and oxygen in molten steel properly and that the adjustment of rimming action was difficult when the content of carbon was low. Adversely when rimming action became weak, it was necessary to promote the rimming action by blowing oxygen into molten steel stream from ladle. Anyhow, it is said that the adjustment of rimming action in mold is relatively easy when the thickness of slab is large. Ultimately, as the result of the tests for 200 heats of casting, many problems remain unsolved for the casting operation and the quality of cast slab. It is considered that it was too early to judge the adaptability of continuous casting for rimmed steel at that time.

On the other hand, active tests and researches on the casting method of rimmed steel and on the properties of cast piece have been advanced in USSR. It was reported that mass-production was possible already in USSR, ${ }^{23)}$ but no report has been published on the practical operation of mass-production.

There is some other trials such as casting of quasirimmed steel by McLouth in U.S.A. or continuous casting of rimmed steel by the use of vacuum degassing process, but none of them has not yet been transferred into mass-production.

Anyhow, every one of the essential characteristics of continuous casting such as rather small section of slab, long region of solidification and rapid cooling in the early period of solidification is not profitalbe to realize the continuous casting of rimmed steel as compared with the case of steel ingot, so that these points become a barrier against its industrialization. Thus there is such a trend that steel obtained by continuous casting is limited almost to killed steel.

\section{Quality of Cast Piece}

At present, the quality of continuously cast steel is generally identical to that of steel made by ingotblooming method. Of course, there is some inferior point partially, but at the same time, they have many superior points. Accordingly, it will be described briefly the characteristics such as the surface quality, the interior quality or the precision of dimension etc.

\section{Surface Quality}

In the continuous casting, mold moves by an oscillating motion. Lubrication between cast steel and mold is performed generally by rapeseed oil for small sectional billet, and by synthetic flux solution for large sectional slab. However, due to the oscillating motion of mold, a lateral linear undulation i.e. oscillation mark remains on the surface of cast piece in accordance with the frequency of the oscillating motion.

Further, longitudinal and transverse cracks are apt to produce on the surface of billet or slab due to unbalance of cooling since cooling from surface is stronger than the case of steel ingot. ${ }^{24,25)}$ Besides, it is same as the case of conventional ingot casting in which residual of slag or pin hole is produced under improper casting condition. ${ }^{26)}$

Accordingly, such a surface defect of billet or slab must be removed prior to the subsequent working, so a scarfer is connected to the continuous casting machine for slab of large capacity in many cases. However, in both cases of slab and billet for ordinary steel, generally it is fed to the subsequent working process without removing or with partially removing the surface defects. Surface defects are carefully removed only for the case of high quality steel. Accordingly, there is a case in which continuous casting is superior than the ingot-blooming method from the aspect of this surface conditioning yield.

\section{Interior Quality}

Continuous casting is performed at present almost by using multiple numbers of coupled drawing rolls. Accordingly, it is necessary to press cast piece by the roll in order to give a drawing force to the roll by frinctional contact between rolls and cast piece. Then, if it is failed to give a proper drawing condition, cracking is apt to produce in the interior of cast piece. ${ }^{27,28)}$

With regard to the segregation of element, only a little is known as compared with that for ingot since continuously cast steel has comparatively small section and also the solidifying speed is higher. In the continuous casting, the casting time becomes comparatively long, but no problem occurs on the segregation even in the long time casting. ${ }^{29)}$ But, it is recently pointed out that sometimes remarkable segregation is formed in a very narrow range along the axial center of slab ${ }^{30-34}$ and this is considered due to the mechanical and the metallurgical factors peculiar to the solidification of continuous casting. ${ }^{35)}$

Next, in the curved-type continuous casting machine, the development of solidified steel shell having a certain curvature has been made. Accordingly, the inclusions brought into liquid steel are caught in the part of curved upper side solidified shell during its floating process. Therefore, in a slab after solidification, the inclusions are accumulated in the intermediate part between inside surface corresponding to the curve of shell and the center of axis. ${ }^{36,37)}$ Of course it is possible to decrease the total amount of inclusions and to reduce the accumulation of inclusions by selecting the casting conditions properly. ${ }^{37}$ ) 
These various defects are apt to be produced especially in continuously cast steel, but it can be reduced up to a certain degree whereat almost no problem exists in the practical operation by selecting the casting conditions properly.

Finally, with regard to the shape and dimension, it is generally said that continuously cast steel has more superior quality than the steel piece obtained by blooming of steel ingot. Though there is some variation in dimension by casting condition, ${ }^{38)}$ it is evident that the desired dimension with little deviation can be gained by casting under the proper conditions. Further, especially in the case of circular sectional billets, a perfect circularity is hardly obtained by the ordinary continuous casting, but it is said that round billets with superior circularity can be produced by the centrifugal continuous casting. ${ }^{14)}$

\section{Ratio of Rolling or Forging Reduction Ap- plied to Cast Piece}

Since the blooming process is omitted in the continuous casting, the rolling or the forging ratio from the cast state to the final product is naturally smaller than that of the conventional ingot-blooming method. Accordingly, it is especially important in the continuous casting to manifest the minimum required rolling or the forging ratio applied to cast piece in order to exhibit normal properties as steel materials. The results of researches on this points reported up to the present are as follows.

\section{Rolling of Billets}

Tensile tests were performed by casting $\mathrm{Si}-\mathrm{Mn}$ spring steel into billets of $130 \mathrm{~mm}$ square, and by cutting out the test pieces from the surface layer and the center parts of semi-products successively during the rolling process. ${ }^{39)}$ The results are shown in Figs. 9 to 12 . From these figures, it is found that there is insufficient parts partially when the rolling ratio (the value of cross-sectional area of cast piece divided by cross-sectional area of tested steel material) is less than 6 , but every parts become to show sufficient properties which are required for steel material if the ratio is more than 10. Accordingly, it is evident that the minimum working ratio in the case of rolling of billets is in the range of $6 \sim 10$. The other results show that the limited working ratio is less than 10 as shown in Table $2 .{ }^{40-50)}$

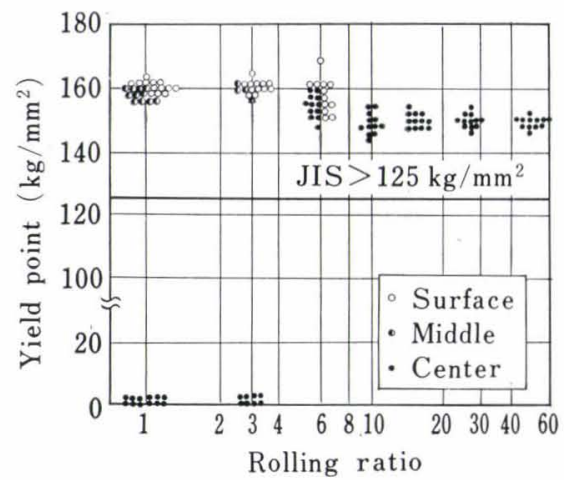

Fig. 9. Effect of rolling ratio upon yielding point ( $\mathrm{Si}-\mathrm{Mn}$ spring steel) ${ }^{39}$ )

\section{Rolling of Slab}

In the case of rolling of slab, it is different from the case of billet on the points that it is mainly one directional rolling and that comparatively low carbon steel is mainly used. Accordingly it shows somewhat lower minimum ratio of rolling as compared with the case of billet.

Materials for plate of $40 \mathrm{~kg} / \mathrm{mm}^{2}$ (tensile strength) class and $50 \mathrm{~kg} / \mathrm{mm}^{2}$ class were cast into slabs of 190

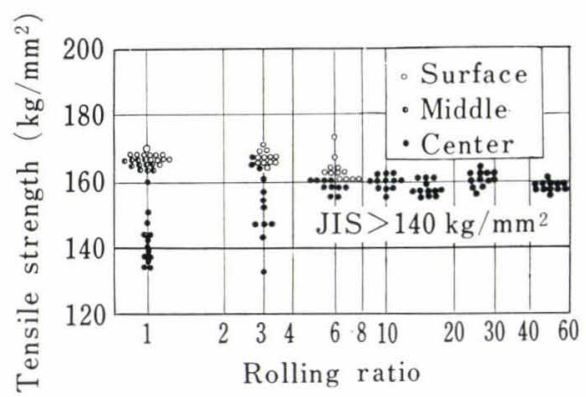

Fig. 10. Effect of rolling ratio upon tensile strength ( $\mathrm{Si}-\mathrm{Mn}$ spring steel) $)^{39)}$

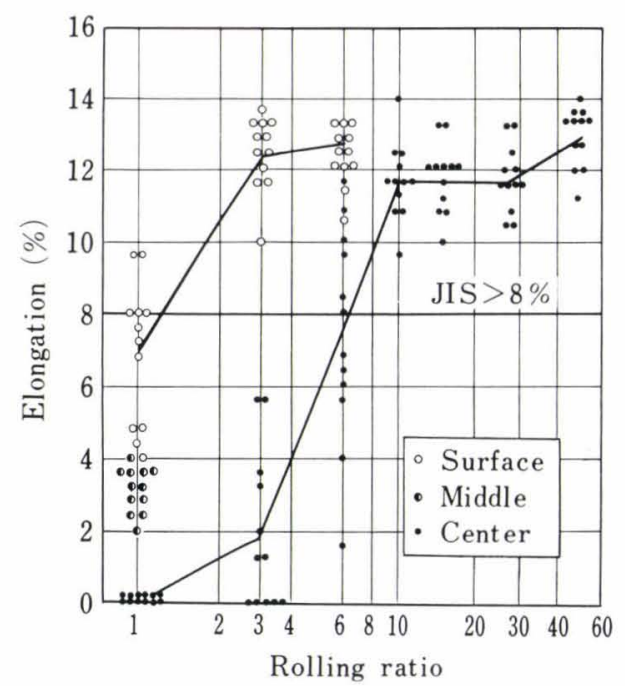

Fig. 11. Effect of rolling ratio upon elongation ( $\mathrm{Si}-\mathrm{Mn}$ spring steel) ${ }^{39}$

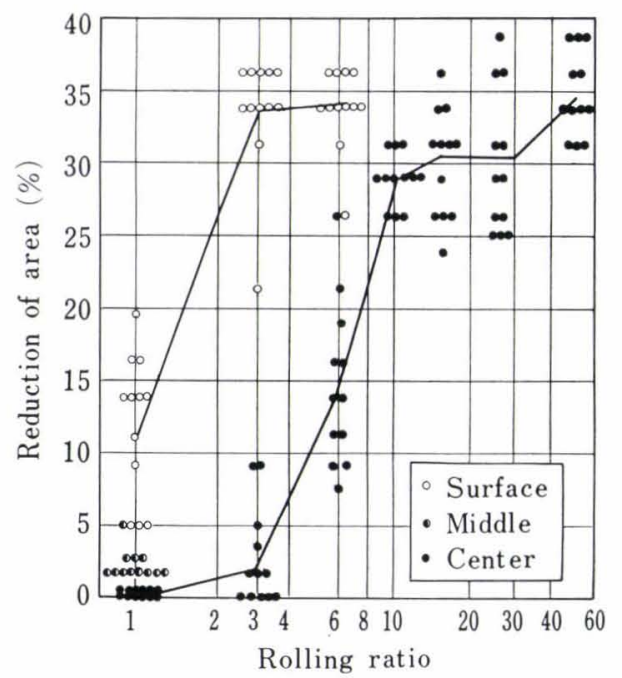

Fig. 12. Effect of rolling ratio upon reduction of area (SiMn spring steel $)^{39}$ ) 
Table 2. Necessary minimum rolling ratio to be applied to continuously cast billet

\begin{tabular}{|c|c|}
\hline Researcher & $\begin{array}{l}\text { Necessary minimum rolling ratio } \\
\text { (cross-sectional area of billet/ } \\
\text { cross-sectional area of product) }\end{array}$ \\
\hline W. B. Pierce ${ }^{40)}$ & $\begin{array}{l}\text { At the ratio of } 4 \text {, primary crystal is } \\
\text { broken, and superior physical proper- } \\
\text { ties can be gained. }\end{array}$ \\
\hline $\begin{array}{l}\text { H. Kosmider, } \\
\text { H. Neuhaus and } \\
\text { A. Weyel }\end{array}$ & $\begin{array}{l}\text { At the ratio of } 1.7 \text {, primary crystal } \\
\text { is broken, and at the ratio of } 3.3 \text {, } \\
\text { blow-hole is diminished. }\end{array}$ \\
\hline J. Hofmaier ${ }^{42)}$ & $\begin{array}{l}\text { The ratio should be of } 6 \sim 12 \text {, and it } \\
\text { may be of } 4 \sim 5 \text { in the case of mak- } \\
\text { ing plate from slab. }\end{array}$ \\
\hline $\begin{array}{l}\text { B. H. C. Waters, } \\
\text { W. H. Pritchard, } \\
\text { A. Braybrook and } \\
\text { G. T. Harris }{ }^{43)}\end{array}$ & $\begin{array}{l}\text { At the ratio of } 5.5 \text {, primary crystal } \\
\text { is diminished and the center cavity } \\
\text { opened at one end is press-contacted, } \\
\text { but segregation of carbide remains } \\
\text { (high speed cutting steel) }\end{array}$ \\
\hline P. Thomas ${ }^{44)}$ & $\begin{array}{l}\text { At the ratio of } 4 \sim 5 \text {, uneven part at } \\
\text { axial center is evened. }\end{array}$ \\
\hline I. M. D. Halliday ${ }^{45)}$ & $\begin{array}{l}\text { At the ratio of } 4 \sim 8 \text {, columnar crystal } \\
\text { is broken. }\end{array}$ \\
\hline $\begin{array}{l}\text { G. Fenton and } \\
\text { J. Pearson }\end{array}$ & $\begin{array}{l}\text { Generally the ratio may be of } 2 \text {, and } \\
\text { it is sufficient at the ratio of } 6.7 \text { even } \\
\text { for severe standard. }\end{array}$ \\
\hline B. Tarmann ${ }^{47)}$ & $\begin{array}{l}\text { At the ratio of } 6 \text {, uniform structure } \\
\text { can be gained (high alloy steel) }\end{array}$ \\
\hline $\begin{array}{l}\text { G. Littlewood and } \\
\text { W. H. Pritchard }\end{array}$ & $\begin{array}{l}\text { At the ratio of } 9 \text {, superior mechanical } \\
\text { properties, up-setting test result and } \\
\text { other general good nature can be } \\
\text { gained. }\end{array}$ \\
\hline $\begin{array}{l}\text { G. Fenton, } \\
\text { G. Littlewood and } \\
\text { J. Zaeytydt }{ }^{49}\end{array}$ & $\begin{array}{l}\text { Some may be the ratio of } 2 \text {, but it } \\
\text { is necessary to be of } 6.7 \text { in the case } \\
\text { severe standard. }\end{array}$ \\
\hline M. Cabane ${ }^{50)}$ & $\begin{array}{l}\text { It is necessary to be the ratio of } 6 \\
\text { for carbon steel and low alloy steel, } \\
8 \text { for stainless steel and heat resisting } \\
\text { steel, } 10 \text { for tool steel in order to keep } \\
\text { enough density. }\end{array}$ \\
\hline
\end{tabular}

$\mathrm{mm}$ thickness, these slabs were rolled in the range of rolling ratio $1 \sim 10$, and then tensile tests and impact tests were made along the rolling and the transverse directions. ${ }^{511}$ The results are shown in Figs. 13 to 16 , and it is found that the minimum rolling ratio is in the range of $3 \sim 5$. The other researches, show nearly the same results. ${ }^{52,53)}$

\section{Forging of Billet}

The results for the examination of various forging processing are as follows. ${ }^{54)}$ Namely, $0.41 \%$ carbon steel was cast into $300 \mathrm{~mm}$ square, forged to $270 \mathrm{~mm}$ diameter or $200 \mathrm{~mm}$ diameter, and test pieces were cut off. Then, up-setting of half reduction was performed. In this case, surface flaw was not produced and the center porosity was diminished. Namely, it is found that the forging property of cast piece is superior as the forging material. Next, applying forging of $300 \mathrm{~mm}-100 \mathrm{~mm}$ diameter onto billet of 300 $\mathrm{mm}$ square, tensile tests were performed for each part. As the results, it is found that each part comes to show the required properties when the processing ratio is more than 2.8 as shown in Fig. 17. In the other researches, similar results are obtained. ${ }^{55}$ )

\section{Properties of Continuously Cast Steel}

Continuously cast steel has been utilized as the steel materials such as steel plate, steel sheet, steel pipe, forgings etc. The quality of continuously cast steel is generally identical or rather superior than that of steel obtained by the conventional steel ingot method. The outline of these will be described in the following section.

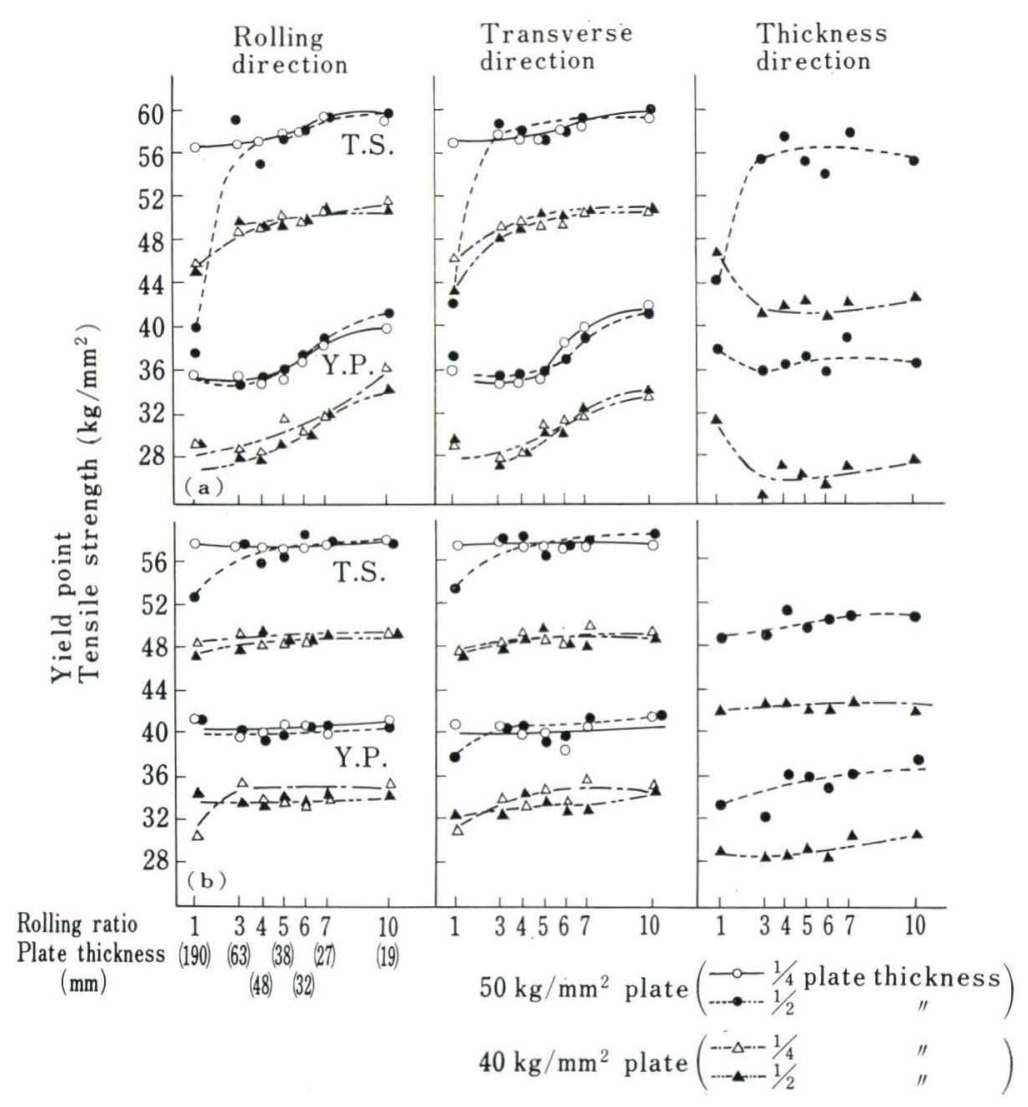

(a) As rolled

(b) Normalized

Fig. 13

Effects of rolling ratio upon yielding point and tensile strength (plate) ${ }^{51}$ 


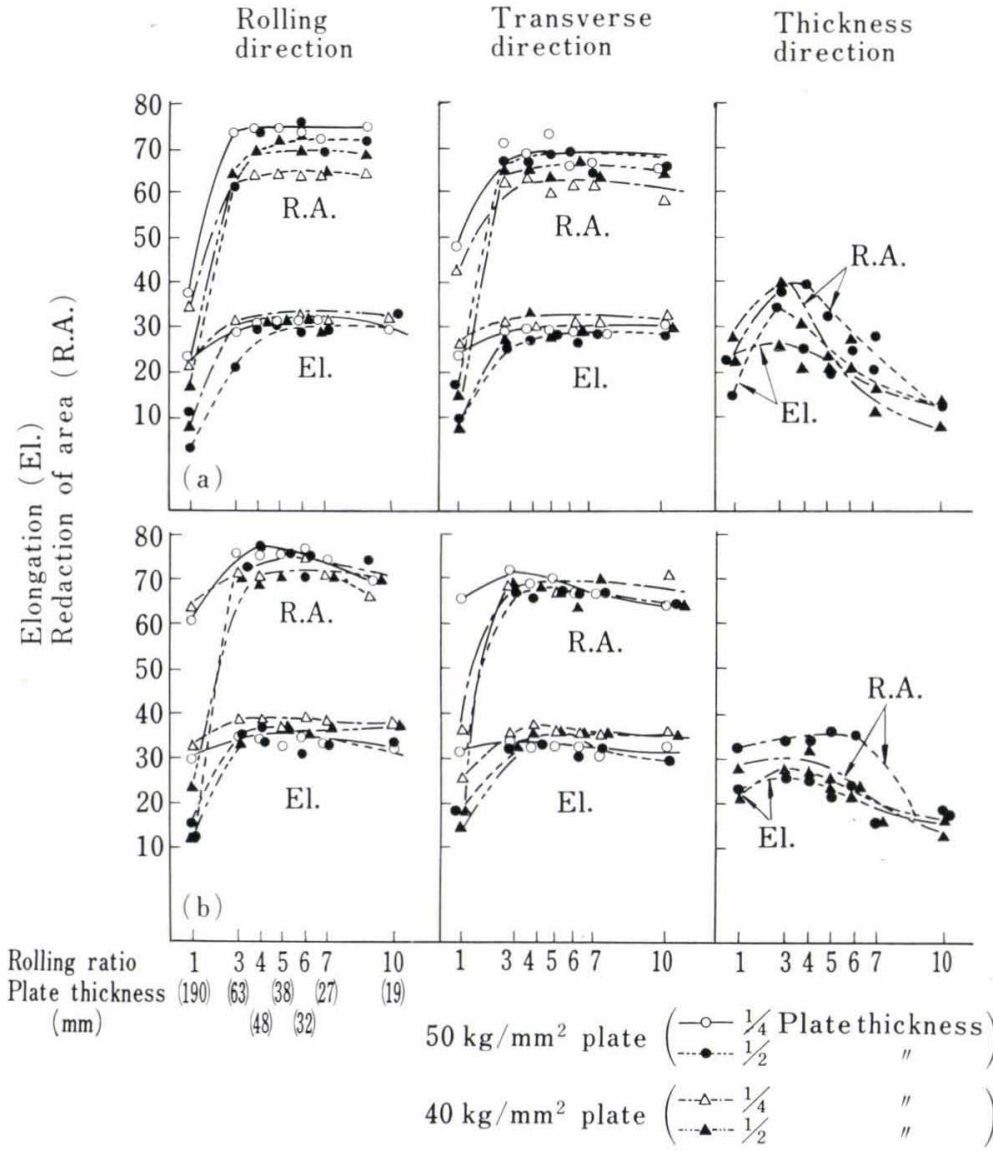
(a) As rolled

(b) Normalized

Fig. 14. Effects of rolling ratio upon elongation and reduction of area (plate) ${ }^{511}$

(a) As rolled

(b) Normalized

Fig. 15. Effect of rolling ratio upon impact property (transition temperature of fracture appearance) (plate) ${ }^{51)}$

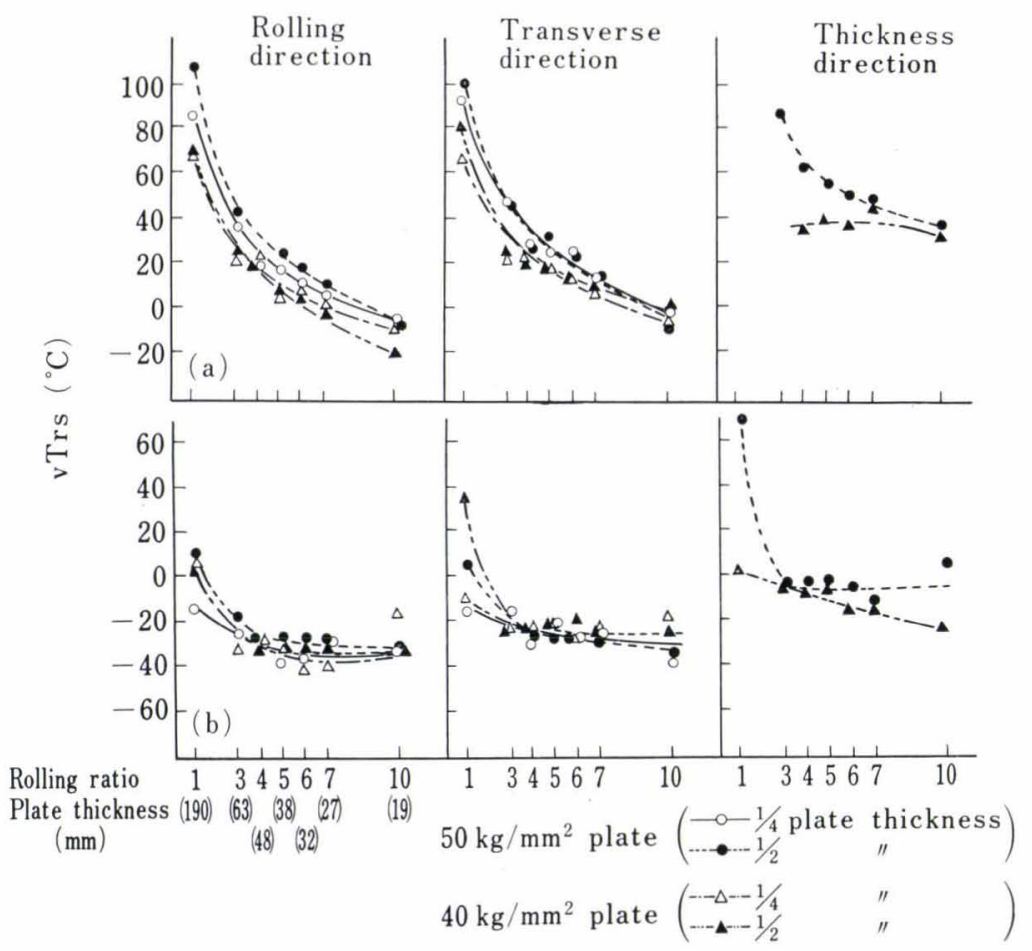

$60 \mathrm{~kg} / \mathrm{mm}^{2}$ class is partially utilized at present. And a fact that there is no negative segregation of $\mathrm{C}$ and $\mathrm{Mn}$ in the bottom part of conventional large-size ingot, or a fact that no large inclusion exists in the bottom part of ingot, is reported as rather superior point than that of ingot material. With regard to large diameter weld pipe material, it is also reported 


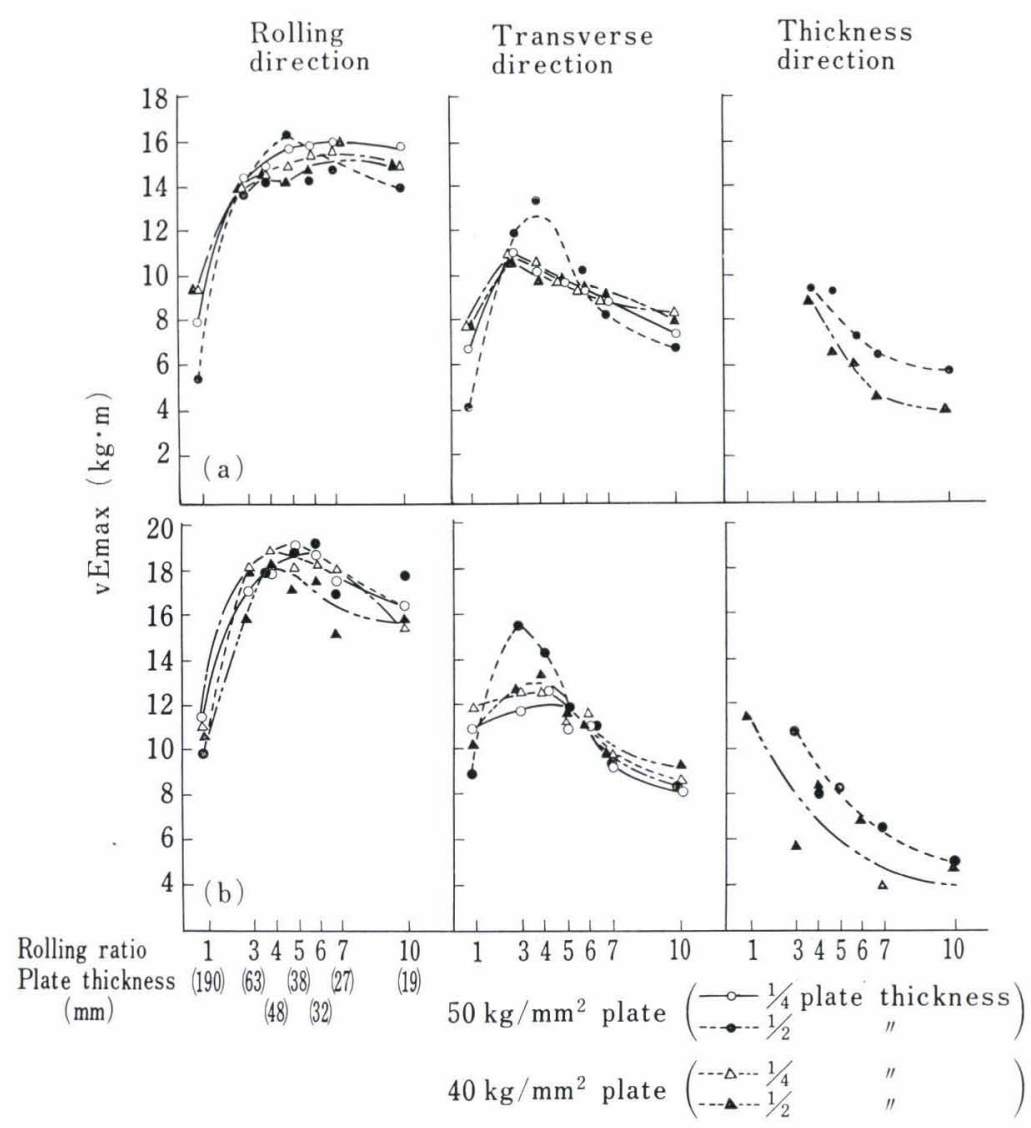

\section{(a) As rolled (b) Normalized}

Fig. 16. Effect of rolling ratio upon impact property (absorbed energy at $100 \%$ shear fracture appearance) (plate) ${ }^{51}$

that manufacture of API-52, 60 or 65 class is possible. ${ }^{53,56)}$

\section{Strip}

Continuously cast steel has been universally used as hot rolled strip or as electric weld pipe. It is reported that continuously cast steel sometimes shows rather superior property in the impact test as compared with the conventional ingot material since nonmetallic inclusion in plate is dispersed as a minute particle. ${ }^{53)}$

\section{Cold Rolled Sheet}

As described above, rimmed steel has not been industrialized by continuous casting. There was a system for manufacturing of cold rolled sheet by heating a pseudo-rimmed slab in an induction heating furnace and then performing rolling, ${ }^{57)}$ but at present, continuously cast slab of Al killed steel or $\mathrm{Si}-\mathrm{Al}$ killed steel is mainly utilized. For example, Al killed steel has such a component, as shown in Fig. 18 and the mechanical properties shown in Fig. 19, are fully satisfactory for deep drawing. ${ }^{58)}$ In this steel grade, it is important to limit the amount of sol. $\mathrm{Al}$ in a proper range and to minimize $\mathrm{Al}_{2} \mathrm{O}_{3}$-base inclusion joined with surplus oxygen especially at the parts nearby the surface of slab, and continuously cast steel having the grade which can be used for tin plate steel has been produced. ${ }^{59)}$

Especially in this steel grade, various countermeasures such as the utilization of vacuum treatment and the adoption of casting under inert atmosphere

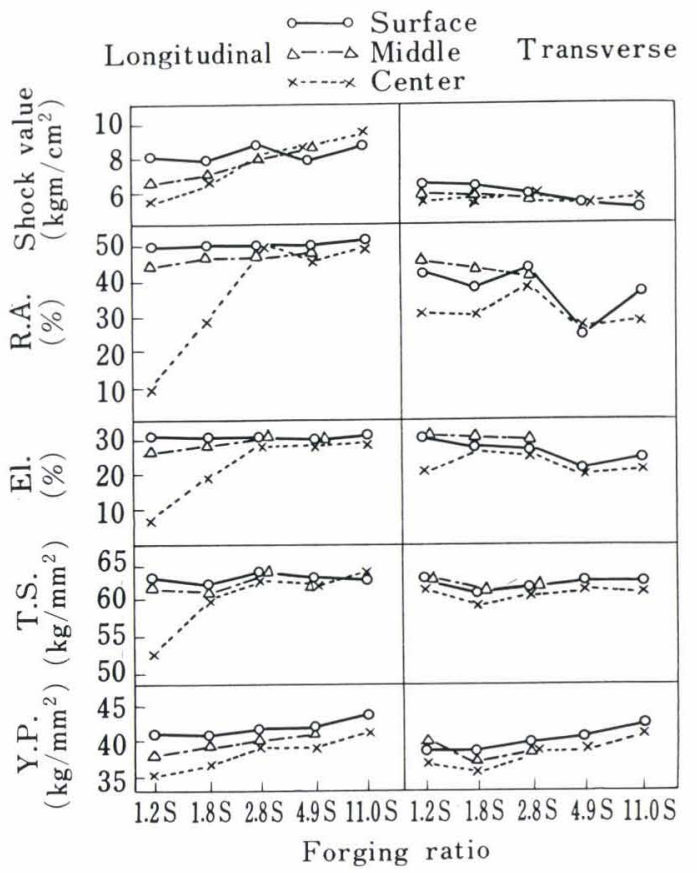

Fig. 17. Effects of forging ratio upon tensile test and impact test $(0.40 \% \mathrm{C})^{54)}$

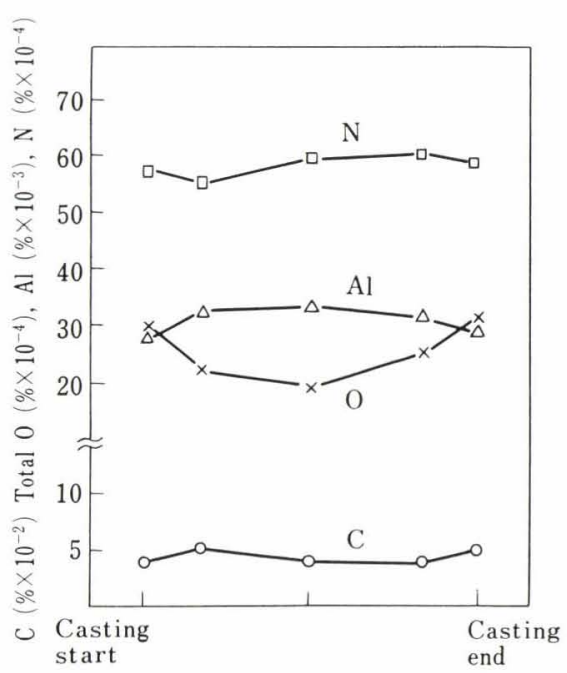

Fig. 18. Composition of Al killed steel (cold rolled sheet $)^{581}$
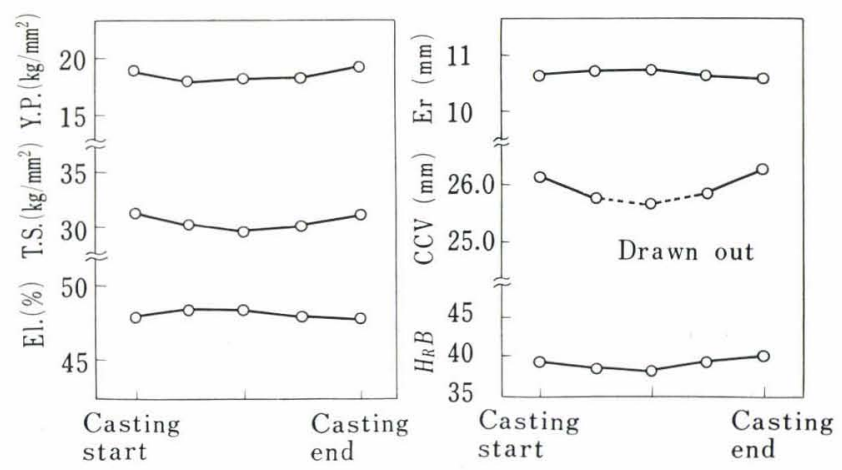

Fig. 19. Mechanical properties of cold rolled sheet by continuous casting (plate thickness $0.7 \mathrm{~mm}$ ) ${ }^{58}$ )

are sometimes devised: Further, by the grade of $\mathrm{Si}-$ Al killed steel, also cold rolled sheet is manufactured, 
but the yielding point and the tensile strength are somewhat high and the elongation is low. It is said that the property for deep drawing is somewhat inferior as compared with conventional Al killed steel. ${ }^{60)}$

\section{Other Steel Sheet and Plate}

As the other special steel, continuous casting of silicon steel for electrical sheet has already been performed. ${ }^{61)}$ A problem on the anticorrosive property of steel plate has been once proposed, but it is manifested that the anticorrosive property of continuously cast steel is identical with that of conventional steel ingot and that there is no inferiority at all from various corrosion tests. ${ }^{62,63)}$

\section{Bar and Wire}

\section{Bar}

In the case of manufacture of bar, mainly of reinforcing bar, continuously cast billet is widely used. The reason why the continuous casting machine for billet is used and bloom is extended rapidly as mentioned above resides mainly in the propagation of continuous casting in this field. Especially, a large quantity of continuously cast bar has been used for the production of high tension deformed bar, and the quality has no inferiority to that of conventional steel ingot material as shown, in Table 3. In addition, it is said that the results of gas pressure welding test also has no problem. ${ }^{64)}$

Next, with regard to structural steel, it has been manifested that its properties are identical to the conventional steel ingot material from the results of tests in which various forging are applied onto bar gained from continuously cast billet through forging and rolling. ${ }^{65)}$ There is many cases used for various kinds of structural steel other than the case mentioned above. ${ }^{66-68)}$

\section{Wire}

With regard to wire, both ordinary wire and highcarbon wire can be manufactured from continuously cast billet. ${ }^{69)}$ Of course, with regard to various product gained by secondary processing of wire, there is also no inferiority at all to the conventional steel ingot material. ${ }^{70)}$ Special manufacturing method in which electro-magnetic agitation is performed in order to improve the tensile ability of PC steel wire has been especially adopted. ${ }^{70)}$

\section{Other Bar and Rod}

As the other bar and rod steel, spring steel and bearing steel ${ }^{71}$ etc. can also be manufactured from continuously cast billet. Especially, with regard to bearing steel, there is some superior points such as the uniformity of the property and minute distribution of carbide or non-metallic inclusion. Further, as a special case, tests relating to $\mathrm{S}$ free-cutting steel have also been carried out.

\section{Pipe}

With regard to welded pipe, the use of continuously cast slab has been propagated successively as described already in the paragraph of plate and strip. As compared with this, it is considered that the propagation of continuous casting in the field of seamless steel pipe is lated one step. In the past, such trials as the direct

Table 3. Chemical composition and mechanical properties of high tension deformed bar by continuous casting

\begin{tabular}{|c|c|c|c|c|c|c|c|c|}
\hline Kind & Analysis position & $\mathrm{C}$ & $\mathrm{Si}$ & Mn & $\mathrm{P}$ & S & $\mathrm{Cu}$ & $\mathrm{C}+\mathrm{Mn} / 6$ \\
\hline \multirow{2}{*}{ Sumibar 35} & Ladle & 0.18 & 0.41 & 1.40 & 0.028 & 0.014 & - & 0.41 \\
\hline & Check & 0.18 & 0.39 & 1.37 & 0.028 & 0.015 & 0.08 & 0.41 \\
\hline \multirow{2}{*}{ Sumibar 40} & Ladle & 0.24 & 0.41 & 1.45 & 0.021 & 0.015 & - & 0.48 \\
\hline & Check & 0.24 & 0.39 & 1.51 & 0.023 & 0.014 & 0.07 & 0.49 \\
\hline Standard & Billet & Size & Specimen & $\begin{array}{c}\text { Yielding } \\
\text { point } \\
\left(\mathrm{kg} / \mathrm{mm}^{2}\right)\end{array}$ & $\begin{array}{c}\text { Tensile } \\
\text { strength } \\
\left(\mathrm{kg} / \mathrm{mm}^{2}\right)\end{array}$ & $\begin{array}{l}\text { Yielding } \\
\text { ratio } \\
(\%)\end{array}$ & $\begin{array}{c}\text { Elongation } \\
(\%)\end{array}$ & $\begin{array}{l}\text { Bending } \\
(4 \mathrm{D}, 188)\end{array}$ \\
\hline \multirow{6}{*}{ Sumibar 35} & Continuously & & 1 & 36 & 55 & 65 & 34 & good \\
\hline & Cast & D 32 & 2 & 35 & 55 & 64 & 34 & good \\
\hline & Material & & 3 & 36 & 55 & 65 & 35 & good \\
\hline & Ingot & & 1 & 39 & 60 & 65 & 34 & good \\
\hline & Blooming & D 32 & 2 & 39 & 60 & 65 & 34 & good \\
\hline & Material & & 3 & 39 & 60 & 65 & 33 & good \\
\hline \multirow{6}{*}{ Sumibar 40} & Continuously & & 1 & 44 & 64 & 67 & 31 & good \\
\hline & Cast & D 32 & 2 & 43 & 64 & 68 & 30 & good \\
\hline & Material & & 3 & 43 & 64 & 68 & 31 & good \\
\hline & Ingot & & 1 & 43 & 69 & 67 & 28 & good \\
\hline & Blooming & D 32 & 2 & 42 & 66 & 68 & 30 & good \\
\hline & Material & & 3 & 43 & 66 & 67 & 37 & good \\
\hline JIS, SD35 & & $\geqq \mathrm{D} 25$ & & $\geqq 35$ & $\geqq 50$ & & $\geqq 20$ & $4 \mathrm{D}, 180^{\circ}$ \\
\hline JIS, SD40 & & $\geqq \mathrm{D} 25$ & & $\geqq 40$ & $\geqq 57$ & & $\geqq 18$ & $5 \mathrm{D}, 180^{\circ}$ \\
\hline
\end{tabular}


manufacturing of pipe from circular sectional billet, ${ }^{72}$ the manufacture of pipe from hollow billet ${ }^{10)}$ or the manufacture of pipe from square sectional billet through transferring it once to a circular section were made, but the case industrialized with ordinary carbon steel pipe other than bearing steel and stainless steel previously described is only a few. The reason resides in the facts that very careful adjustment of machine is required in order to gain stably a sound cast billet with circular section, and that the merit of improving the yield by continuous casting is reduced to a half when it is transferred once to a circular section from a square section through rough rolling.

As a method which responses to a solution of these problems, centrifugal continuous casting is under industrialization. In Japan, an installation of industrial scale by this method was already installed in 1974 , and it is expected that one new situation will be opened.

\section{Conclusion}

Cast pieces supplied by continuous casting of steel can be made to final products through substantially similar working for product to the conventional process by omitting the blooming process and without changing the conventional processing. And it was described, with regard to the product thus gained, that the quality of product is identical or rather superior sometimes to that of conventional steel ingotblooming method in spite of the fact that the working ratio is less than that of conventional method. It is considered that steel products by continuous casting method will be propagated more and more in response to the desire of pursuing the merits of omission of the process and of the improvement in yield, of course, and to the trends of the times such as laborsaving, energy-saving and mechanization of operation.

\section{REFERENCES}

1) H. Gotthelf, R. Klages, H. W. Kreutzer, K. Nürnberg, H. Schäfer and C. Weidemüller: Stahl u. Eisen, 93 (1973), 714.

2) C. Holden: JISI, 207 (1969), 806.

3) W. H. Pritchard and M. C. D. Hobbs: Steel Times Annual Rev., (1966), 209.

4) J. Pearson: Iron Steel Inst. Spec. Rep., No. 89 (1965), 88.

5) G. S. Lucenti: Iron Steel Eng., 46 (1969), 83.

6) J. Selron: Iron Age, 175 (1955), 88.

7) K. Ushijima: Tetsu-to-Hagané, 47 (1961), 24

8) K. Ushijima: Tetsu-to-Hagané, 48 (1962), 3.

9) For example, Seitetsu Kenkyu, 261 (1967), 3.

10) U. Peterson, K. G. Speith and A. Bungeroth: Stahl u. Eisen, 86 (1966), 333.

11) Steel, 158 (1966), 25.

12) B. Tarmann: Iron Age Metolworking International, Aug. (1966), 22

13) Iron Age, 211 (1973), 48.

14) Kawasaki Technical Review, 44 (1971), 75.

15) J. E. McConnell: Aime O-H Proc., 55 (1972), 56.

16) E. S. Szekeres: Aime O-H Proc., 55 (1972), 48.

17) S. Noritomi, T. Takagi, M. Matsukubo, T. Noda and K. Tazawa: Tetsu-to-Hagané, 59 (1973), 81.

18) A. V. Wiebel: Blast Furn. Steel Pl., 57 (1969), 741.

19) 33/The Magazine of Metals Proc., 7 (1969), 96.
20) R. Johnson, J. W. Middleton and D. Ford: Iron Steel Inst. Spec., No. 89 (1965), 52.

21) R. W. Evans: Iron Steel Inst. Spec., No. 89 (1965), 91.

22) K. H. Bauer: Iron Steel Inst. Spec., No. 89 (1965), 88.

23) For example, G. M. Itskovich and V. B. Gankin: Stal in Eng., 6 (1961), 407.

24) Y. Aketa, K. Sasaki and K. Ushijima: Tetsu-to-Hagané, 45 (1959), 23.

25) Y. Aketa and K. Ushijima: Tetsu-to-Hagané, 46 (1960), 3.

26) H. Mori: Tetsu-to-Hagané, 58 (1972), 1511.

27) Y. Aketa and K. Ushijima: Tetsu-to-Hagané, 46 (1960), 15 .

28) K. Ushijima: Tetsu-to-Hagané, 47 (1961), 24.

29) Y. Aketa and K. Ushijima: Tetsu-to-Hagané, 48 (1962), 11.

30) S. Nemoto, T. Kawawa, H. Sato and S. Miyahara: Tetsuto-Hagané, 58 (1972), 148.

31) K. Asano, T. Hiromota and T. Ohashi: Tetsu-to-Hagané, 59 (1973), 83

32) Y. Umeda, H. Nashiwa, K. Yasumoto and M. Tokuda: Tetsu-to-Hagané, 59 (1973), 81

33) Y. Abe, S. Yamaji, S. Shibuya and K. Shinoda: Tetsuto-Hagané, 59 (1973), 84.

34) S. Takaishi, H. Murata, T. Komai and H. Sekihara: Tetsu-to-Hagané, 59 (1973), 103.

35) T. Takahashi and A. Kudo: Tetsu-to-Hagané, 59 (1973), 101.

36) H. Kumai, T. Hiromoto, T. Ohashi, H. Matsunaga and T. Ono: Tetsu-to-Hagané, 59 (1973), 106.

37) H. Kumai, T. Hiromoto, T. Ohashi, H. Matsunaga and T. Ono: Tetsu-to-Hagané, 59 (1973), 107.

38) T. Inoue, H. Naokawa, H. Niimi and K. Noro: Tetsu-toHagané, 58 (1972), 145

39) Y. Aketa and K. Ushijima: Tetsu-to-Hagané, 48 (1962), 11.

40) W. B. Pierce: Blast Furn. Steel Pl., 41 (1953), 1301.

41) H. Kosmider, H. Neuhaus and A. Weyel: Stahl u. Eisen, 76 (1956), 668.

42) J. Hofmaier: Stahl u. Eisen, 77 (1957), 69.

43) B. H. C. Waters, W. H. Pritchard, A. Braybrook and G. T. Harris: JISI, 190 (1958), 233.

44) P. Thomas: JISI, 190 (1958), 123.

45) I. M. D. Halliday: Iron Steel, 191 (1959), 121.

46) G. Fenton and J. Pearson: JISI, 189 (1958), 160.

47) B. Tarmann: Radex Rundschau, (1961), 579.

48) G. Littlewood, and W. H. Pritchard: Iron and Coal, 183 (1961), 1381.

49) G. Fenton, G. Littlewood and A. Zaeytydt: Iron and Coal Trades Rev., 182 (1961), 681.

50) M. Cabane: Steel and Coal, 184 (1962), 805.

51) S. Hasebe, H. Izeki, S. Hamanaka and M. Nakamura: Sumitomo Metals, 24 (1972), 79.

$52)$ S. Nemoto, T. Shimizu, S. Sasaka, N. Takeda, Y. Fukuda and K. Ota: Nippon Kokan Technical Report, 46 (1969), 27.

53) T. Matsumoto, T. Saito and S. Miyoshi: Nippon Kokan Technical Report, 57 (1972), 93.

54) T. Nagai, T. Nozaki, M. Miura and K. Ohara: $R$ and $D$, 19 (1969), 24

55) M. Signora: JISI, 195 (1960), 253.

56) For example, S. Nemoto: Nippon Kokan Technical Report, 50 (1970), 27.

57) B. McArthur: Iron Steel Eng., 45 (1968), 74.

58) T. Iwasaki: Kawasaki Steel Technical Report, 5 (1973), 77.

59) T. B. Winkler and J. W. Halley: Joint Development of the Strand Casting Progress for Quality Sheet and Tin Mill Products AISI, (1971), Oct. 14.

60) J. Kubodera: No. 8 Nishiyama Memorial Lecture, ISIJ, (1969), 27. 
61) Continuous Casting Group: Ishikawajima-Harima Engineering Review, 11 (1971), 339.

62) G. Kuliberg: Iron Steel, 45 (1972), 173.

63) N. Kaneko, T. Kawawa, I. Matsushima, Y. Ishizu and Y. Fukuda: Nippon Kokan Technical Report, 43 (1968), 37.

64) K. Kajiyama, O. Setoguchi and K. Miura: Sumitomo Metals, 22 (1970), 111.

65) T. Nagai, T. Nozaki, M. Miura and K. Ohara: $R \& D$, 19 (1969), 24.

66) L. Baecker and P. Gosselin: J. Metals, 23 (1971), 4.

67) A. L. Collins: Concast Newes, 9 (1970), 4.
68) O. Steinhauer and R. Jauch: Stahl u. Eisen, 87 (1967), 374.

69) Y. Motoki, J. Fukutomi, K. Uesaki and G. Kudo: Tetsuto-Hagané, 57 (1971), 110.

70) H. Iwata, K. Yamada, T. Yamada and R. Hayashi: Tetsu-to-Hagané, 59 (1973), 99.

71) K. Okamoto and S. Shiyuki: Seitetsu Kenkyu, 261 (1967), 35.

72) J. M. Kay, J. W. Menter and C. Holden: Iron Steel Inst. Spec. Rep., No. 89 (1965), 23. 